\title{
Enhancing our understanding of physical activity and wellbeing with a lifespan perspective
}

\author{
Amanda L. Hyde · Jaclyn P. Maher · Steriani Elavsky
}

\begin{abstract}
Physical activity might be a viable tool for enhancing mental wellbeing because, in general, physical activity has been found to be related to more positive affect and higher satisfaction with life. The way we think, feel, and act changes with age, so it may be that physical activity, wellbeing, and the link between physical activity and wellbeing change with age too. Without consideration for developmental changes, study findings are decontextualized and difficult to translate into people's lives. Aiming to become better equipped to use physical activity as a tool to intervene with wellbeing, we explored a lifespan perspective of physical activity and wellbeing. In this review, we (1) discuss physical activity, wellbeing, and the link between physical activity and wellbeing at different life stages, (2) highlight the need to consider interpersonal and intrapersonal differences in these constructs, and (3) identify gaps in the literature that, if filled, would further enhance our understanding of physical activity and wellbeing across the lifespan.
\end{abstract}

Keywords: development, life stages, satisfaction with life, affect, exercise, wellbeing

\section{Introduction}

Physical activity significantly enhances mental wellbeing at any age (Physical Activity Guidelines Advisory Committee, 2008), but affect, behavior, and cognition is subject to change across the lifespan, and these developmental changes may result in differences in physical activity, wellbeing, and in the link between physical activity and wellbeing across life stages. Most research on physical activity and wellbeing has been conducted on samples with restricted age ranges, such as middle-aged women (e.g., Elavsky \& McAuley, 2005) or older adults (e.g., Arent, Landers, \& Etnier, 2000; McAuley et al., 2006). This narrative review aims to put forth a lifespan perspective by presenting previous research findings about physical activity and wellbeing at different life stages and highlighting future avenues of research that are necessary to fill gaps in the literature.

Based on the work of Diener (1984) and Diener, Suh, Lucas, and Smith (1999), we define wellbeing as the preponderance of positivity of affect and high satisfaction with life. In general, people highly value their wellbeing and strive to be happy and satisfied with life (Diener, 2000). Physical activity may be a viable tool for enhancing wellbeing because, in general, physical activity has been found to be related to more positive affect and higher satisfaction with life (Arent et al., 2000; Ekkekakis, Parfitt, \& Petruzzello, 2011; Ekkekakis, 2003; Netz, Wu, Becker, \& Tenenbaum, 2005; Penedo \& Dahn, 2005; Rejeski \& Mihalko, 2001); however, the magnitude of the effects vary widely across studies and individuals. For example, Netz and colleagues (2005) found that age moderated the effect of physical activity on wellbeing in older 
adults, with larger effects seen for people around age 65 years compared to people around age 74 years. Without considering context, such as life stage, this variable evidence cannot be easily translated into people's lives. It is our contention that a better understanding of physical activity and wellbeing will be reached through applying a lifespan perspective.

A lifespan perspective can help contextualize physical activity and wellbeing into the always-evolving physical, psychological, biological, and environmental factors that manifest in life (Baltes, 1987). The key suppositions of a lifespan perspective include the following: (1) development is a lifelong process, with changes occurring throughout the entire lifespan; (2) change is multifaceted, manifesting growths and declines of biological, personal, and environmental factors; (3) development is highly variable between people (i.e., individual differences) and across time (i.e., intrapersonal changes); and (4) development is embedded in multiple aspects of life, represented by age-related differences, social customs, and historical influences. A lifespan perspective details general trends across life and how characteristics of an individual and differences in life experiences can lead to deviations from general trends (Baltes, Reese, \& Lipsitt, 1980; Baltes, 1987). The initial step toward taking a lifespan perspective of physical activity and wellbeing is to determine the general trends of physical activity, wellbeing, and the relation between these two constructs across the stages of life. Figures 1 and 2 (below) are examples of lifespan perspective of physical activity and wellbeing, respectively. Depicted in these schemas are general trends as well as examples of individual differences, life events, and daily changes that can impact these trajectories. Following, we discuss previous research on general trends in physical activity and wellbeing and links between physical activity and wellbeing across life stages.

\section{General trends in physical activity and wellbeing across life stages}

\subsection{Childhood (3-9 years)}

\subsubsection{Physical activity}

There is limited research tracking physical activity from childhood across the entire lifespan, but studies of prevalence rates of physical activity in children and trends from childhood to adolescence suggest childhood is characterized by higher levels of physical activity than other times in the lifespan. Based on a cross-sectional study using accelerometers, it was found that children were over five times more likely to participate in 60 minutes of physical activity per day than adolescents or adults (Troiano et al., 2008). Pate and colleagues (2002) found that over $90 \%$ of school-aged children (7-16 years old) were engaging in at least 30 minutes of moderate physical activity per day on five or more days a week. Overall, the evidence shows that children are more likely to be meeting or exceeding physical activity guidelines than populations of other ages; however, most children are still not as physically active as they should be. The American Physical Activity Guidelines recommend children participate in 60 minutes of physical activity daily (Physical Activity Guidelines Advisory Committee, 2008).

Childhood may have higher rates of physical activity than other life stages because there are fewer barriers to physical activity during this time in the lifespan. Some of the most commonly reported barriers to physical activity do not become a problem until well after childhood. For example, people commonly report that they are not physically active because of a lack of available time, feeling too tired, or having no motivation (Brownson, Baker, Housemann, Brennan, \& Bacak, 2001). Childhood, however, is characterized by free time, energy, and an intrinsic value for play (Hughes, 1995). Beyond a lack of barriers, greater intrinsic motivation might explain high levels of physical activity in children. It is not beliefs in 
the health, social, or physical benefits of physical activity that are associated with more physical activity in childhood (Strauss, Rodzilsky, Burack, \& Colin, 2001); rather, children are physically active when they enjoy the activity and get a sense of accomplishment out of it (Weiss, 2000). As a time of few barriers and greater intrinsic motivation to be physically active, childhood is more amenable to high levels of physical activity participation than are other developmental stages.

\subsubsection{Wellbeing}

It remains ambiguous how wellbeing in childhood compares to other stages in life because studies on lifespan trajectories of wellbeing tend to start in early adulthood. Future research is needed that compares wellbeing in childhood to wellbeing in other life stages. Although direct comparisons have not been made with other life stages, studies suggest children are mostly happy (Holder, Coleman, \& Wallace, 2010; Holder \& Klassen, 2010; Larson \& LampmanPetraitis, 1989) and satisfied with their lives (Proctor, Linley, \& Maltby, 2009). Some evidence suggests wellbeing may start to decrease around 10 years old with the transition into adolescence (e.g., Greene, 1990; Larson \& Lampman-Petraitis, 1989).

The tendency for children to have high wellbeing may be due to the amount of leisure time available during this stage of the lifespan and how children fill this time. Childhood is characterized by ample free time to play (Hughes, 1995). This opportunity for spending a large amount of time in freely selected, enjoyable, unencumbered activities can lead to positive affect and, because leisure is a major component of overall satisfaction (Argyle, 2001; Caldwell, 2005), play might also enhance satisfaction with life. Another reason children might generally have high wellbeing is the availability of opportunities to acquire senses of autonomy, relatedness, and competence-basic needs that are strongly connected to wellbeing (Ryan \& Deci, 2000). Such opportunities are present when children receive encouragement from important others to learn independence and develop new skills. These same opportunities to build motor, language, and cognitive skills are typically not as richly available after the transition from childhood.

\subsubsection{Physical activity and wellbeing}

There is well-documented evidence that physical activity is associated with aspects of good mental health in children, including high self-esteem, low symptoms of anxiety and depression, and low stress (Crews, Lochbaum, \& Landers, 2004; Gruber, 1986; Mutrie \& Parfitt, 1998; Parfitt \& Eston, 2005; Strong et al., 2005), but there is little research on the effects of physical activity on satisfaction with life or affect in children. It has been shown that physical activity can acutely enhance mood in children (Williamson, Dewey, \& Steinberg, 2001), and although life satisfaction can meaningfully be measured in children as young as age six (Huebner, 2004), little is known about the effects of physical activity on satisfaction with life or the long-term affective consequences of physical activity in children. Future research is needed to determine the links between physical activity and wellbeing in childhood.

\subsection{Adolescence (10-17 years)}

\subsubsection{Physical activity}

There is generally a steep decrease in physical activity seen across the teenage years (Caspersen, Pereira, \& Curran, 2000; Kjønniksen, Torsheim, \& Wold, 2008; Riddoch et al., 2004; Sallis, Prochaska, \& Taylor, 2000; Telama \& Yang, 2000; Trost, Pate, et al., 2002). This has been 
shown in longitudinal studies of both self-reported (Kjønniksen et al., 2008; Telama \& Yang, 2000) and directly-assessed physical activity (Riddoch et al., 2004; Trost, Owen, Bauman, Sallis, \& Brown, 2002). As a result of the decline in physical activity across adolescence, the percentage of people participating in regular moderate and vigorous physical activity significantly drops within the age range of 15 to 18 years old (Pate et al., 2002; Troiano et al., 2008). Adolescence is a time of transitions, and unfortunately it seems these transitions include a decline in physical activity. Objective physical activity surveillance indicates that only $8 \%$ of adolescents are participating in an average of at least 60 minutes of physical activity per day (Troiano et al., 2008).

It may be that declines in physical activity across adolescence are due to shifts in time constraints, received support for playful behavior, or preferences and motivations for physical activities during this life stage. Expectations for less playful behavior and more work- or school-related demands can result in less allocated time for physical activity (Larson \& Verma, 1999). Additionally, declines in physical activity competencies and preferences for physical activities have been shown to explain declines in physical activity behavior in the early adolescent years (Sallis, Alcaraz, McKenzie, \& Hovell, 1999). Priorities, responsibilities, and attitudes shift dramatically in adolescence and it seems that physical activity levels suffer because of it.

\subsubsection{Wellbeing}

Adolescence is typically characterized by lower levels of wellbeing than in childhood. In fact, satisfaction with life declines from age 11 to 16 (Goldbeck, Schmitz, Besier, Herschbach, \& Henrich, 2007) and, although most adolescents report they are satisfied with their life overall, a noteworthy $11 \%$ of adolescents report being highly dissatisfied (Huebner, Drane, \& Valois, 2000). In general, affect also becomes less positive across the transition from childhood to adolescence and continues to decline until late adolescence (Greene, 1990; Larson, Moneta, Richards, \& Wilson, 2002; Moneta, Schneider, \& Csikszentmihalyi, 2001).

Neurobiological, cognitive, and environmental shifts may each be responsible for the decline in wellbeing that is typical of adolescence. The brain systems responsible for emotional regulation, risk-taking behaviors, and elevations of depression and anxiety undergo structural and functional evolution during adolescence which may result in decreased wellbeing (Casey, Jones, \& Hare, 2008; Ernst, Pine, \& Hardin, 2006; Yurgelun-Todd, 2007). Such neurobiological changes may also co-occur with changes of perceptions and motivation that enhance the decline of wellbeing. For example, in adolescence, mental health can become highly contingent on popularity and peer acceptance (Bukowski, Hoza, \& Boivin, 1993); therefore environmental factors such as peer victimization can have devastating consequences for an adolescent's satisfaction with life and affect (Martin \& Huebner, 2007). It has also been postulated that the reduction in positivity of affect seen in adolescence may be a result of an increase in exposure to stressful events (Larson \& Ham, 1993). All the developmental changes occurring in adolescence can make coping with stressors a tumultuous task and, as a result, an individual's wellbeing can suffer.

\subsubsection{Physical activity and wellbeing}

In adolescence, both physical activity and wellbeing tend to be declining. This makes it essential that we understand the link between physical activity and wellbeing during this stage of life. A study has shown that adolescents who are not physically active have lower levels of satisfaction of life than their more physically active peers (Valois, Zullig, Huebner, \& Drane, 
2004). Little is understood about the long-term affective consequences of physical activity, but some studies have shown acute positive affective responses to physical activity in adolescents (Schneider, Dunn, \& Cooper, 2009; Schneider \& Graham, 2009). Future research is necessary to further establish the link between physical activity and positive affect in adolescence. Although relevant studies are limited in number, the existing evidence base suggests that physical activity is linked to wellbeing in adolescence.

\subsection{Emerging adulthood (18-25 years)}

\subsubsection{Physical activity}

Cross-sectional and longitudinal research shows that physical activity levels during emerging adulthood continue to follow the decreasing trend that emerged in adolescence (Caspersen et al., 2000; Kjønniksen et al., 2008; Troiano et al., 2008). The decline is steepest around age 18 years, with the exception that certain physical activities such as jogging alone, cycling, and some organized sports tend to strongly track across this stage of life (Kjønniksen et al., 2008). Approximately one-third of emerging adults engage in no leisure-time physical activity (Barnes, 2007; Pleis, Lucas, \& Ward, 2009).

Given that emerging adulthood is characterized by shifting values and goals, it would not be surprising if physical activity motivation was also shown to shift during emerging adulthood. It may be that whereas physical activity is regulated by intrinsic motivation at younger ages (Weiss, 2000), physical activity may be more regulated by extrinsic motivation (e.g., improving appearance, weight loss) in emerging adults. Additionally, emerging adults may be faced with more barriers to physical activity than were present at an earlier age. The commonly listed barriers of a lack of time, energy, or motivation may be especially relevant during emerging adulthood when individuals are taking on many other responsibilities and priorities (Brownson et al., 2001). In addition to shifts in motivation, physical activity may decline during emerging adulthood due to disrupted habits, as research has shown that habits regulate physical activity (Gardner, De Bruijn, \& Lally, 2011; Verplanken \& Melkevik, 2008). Habits are automatic behavioral responses to contextual cues (e.g., exercising every day after high school), so when transitions occur in which contextual cues are displaced (e.g., graduating high school), habits may be displaced and physical activity levels suffer.

\subsubsection{Wellbeing}

Emerging adulthood is characterized by a sharp decline in wellbeing (Carstensen et al., 2011; Stone, Schwartz, Broderick, \& Deaton, 2010). Both cross-sectional and longitudinal studies have shown that people have fewer positive emotional experiences during emerging adulthood than during adulthood (Carstensen et al., 2011). Satisfaction with life steeply declines in emerging adulthood from rates that are not recovered again until older age (Stone et al., 2010). At a time of life that should be full of excitement and vitality, emerging adulthood is characterized by typically low positive affect and declines in satisfaction with life.

Low levels of positive affect may be the result of an inability to regulate the multitude of emotional experiences that can occur at this age (Carstensen et al., 2011). Also, emerging adults are still developing effective emotional regulation skills and can be faced with an onslaught of hardships related to accepting responsibility, making major life decisions, and becoming financially independent (Arnett, 2000). Additionally, the socioemotional selectivity theory proposes that people experience less positive emotions at this early stage of adulthood because time is perceived as open-ended, so knowledge-attaining goals are prioritized over emotional 
goals (Carstensen, Isaacowitz, \& Charles, 1999). Satisfaction with life may also decrease during emerging adulthood because of the risks associated with exploration. Failed career, scholarly, or romantic efforts may lead to discouragement and dissatisfaction with life. Emerging adulthood is a time of development and growth; unfortunately, it seems that these challenges may have detrimental consequences for wellbeing.

\subsubsection{Physical activity and wellbeing}

One study found that when emerging adults participated in more physical activity than typical, their satisfaction with life was also higher than usual (Maher et al., 2012). Another study found that emerging adults who were more physically active tended to experience more pleasantactivated feelings (e.g., excitement, happiness) than emerging adults who were less active; and that when emerging adults were more physically active than was typical for them, they experienced more pleasant-activated feelings (Hyde, Conroy, Pincus, \& Ram, 2011). Studies have also linked physical activity to increases in positive affect in emerging adults (McIntyre \& Watson, 1990; Watson, 1988). Primarily, research on physical activity and wellbeing in emerging adulthood has focused on college students; therefore the results cannot be generalized to the "forgotten half" of emerging adults who do not attend college (Halperin, 2001).

\subsection{Adulthood (26-65 years)}

\subsubsection{Physical activity}

The decline in physical activity seen in adolescence and emerging adulthood levels off in adulthood and physical activity levels remain relatively stable at a low level until gradually declining again nearing the transition to older age (Caspersen et al., 2000; Troiano et al., 2008; Tucker, Welk, \& Beyler, 2011). At the start of adulthood, 32\% of adults report engaging in no leisure time physical activity, and this number increases to around $40 \%$ at the conclusion of adulthood (Barnes, 2007; Tucker et al., 2011). Directly-measured physical activity data show that fewer than $5 \%$ of adults are participating in an average of 30 minutes of physical activity per day (Troiano et al., 2008).

Physical activity may be deprioritized during adulthood. Initiatives for being physically active are oftentimes self-oriented (e.g., I want to be healthier, lose weight, or have fun); such goals are typically displaced by more family-oriented goals (e.g., I want to raise healthy children, financially support my family, or be a good spouse) during adulthood (Nurmi, 1992). When physical activity is perceived as less important than other responsibilities, it is compromised as a result of lack of time and resources. Indeed, lack of time and energy are the primary barriers to physical activity reported by adults (Brownson et al., 2001). The typically low levels of physical activity characteristic of adulthood may be stable during adulthood because daily life tends to be more regularly structured than during other life stages so habits are likely to be developed and sustained (Verplanken \& Wood, 2006; Wood \& Neal, 2007). Priorities and habits in adulthood are typically not correspondent with high levels of physical activity, which may explain why stable low physical activity levels are present in this life stage.

\subsubsection{Wellbeing}

Adults tend to have a stronger preponderance of positive affect than do emerging adults and this positive trend continues throughout adulthood (Carstensen et al., 2011; Carstensen, Pasupathi, Mayr, \& Nesselroade, 2000; Charles, Reynolds, \& Gatz, 2001; Diener \& Diener, 1996). 
The preponderance of positive affect is a result of there being less negative affect, rather than just an increase of positive affect. There are mixed results concerning the exact trajectory of satisfaction with life across adulthood. An assortment of studies has shown that satisfaction with life decreases, increases, or is stable across adulthood (Diener \& Suh, 1997; Herzog \& Rodgers, 1981; Horley \& Lavery, 1995; Lang \& Heckhausen, 2001; Mroczek \& Spiro, 2005; Prenda \& Lachman, 2001; Stone et al., 2010). As evidenced from the disparate findings of these studies, the trajectory of satisfaction with life is unclear. It may be that satisfaction with life varies more between-persons in adulthood than in other life stages. Fortunately, the majority of adults are happy and satisfied with life (Diener \& Diener, 1996; Diener et al., 1999).

The positive shift in trajectory of wellbeing that occurs in adulthood is proposed to be a result of motivational and emotion regulation developmental changes. The socioemotional selectivity theory suggests that as they age, adults begin to perceive time as limited and shift motivational focus from knowledge acquisition goals to emotional goals (Carstensen et al., 2011, 1999). As a result, adults start avoiding situations that likely result in negative emotional experiences and rather focus on the people and scenarios that tend to lead to more positive emotional experiences. Additionally, there is evidence to suggest that adults use more effective emotional regulation strategies than emerging adults (John \& Gross, 2004). Adults may regulate emotions more by changing the way they think about situations and less by changing the way they act than emerging adults. Emotion regulation develops in adaptive ways in adulthood, which leads to better wellbeing; however, there is growing research in recent years showing that stress reactivity and mood instability increase with age (Sliwinski, Almeida, Smyth, \& Stawski, 2009). This research suggests that the observed increase in positivity of affect present in adulthood is due to adjusting goals or expectations and avoiding stressful situations rather than the result of better emotional regulation.

\subsubsection{Physical activity and wellbeing}

Physical activity has been shown to predict positive affect in survey (Stephens, 1988), intervention (Reed \& Buck, 2009; Reed \& Ones, 2006), and experience sampling (Gauvin, Rejeski, \& Norris, 1996; Hyde, Conroy, Pincus, \& Ram, 2011) studies. Most adult studies on physical activity and satisfaction with life have focused on subpopulations such as cancer patients and survivors and middle-aged women (e.g., Courneya \& Friedenreich, 1999; Elavsky \& McAuley, 2005). For example, Elavsky and McAuley (2005) studied perimenopausal and post-menopausal women and found that the relation between physical activity and life satisfaction was mediated by physical self-worth and menopausal symptoms. Future research on broader populations of adults is necessary to generalize these results to a wider range of adults.

\subsection{Old age (65 years and older)}

\subsubsection{Physical activity}

Although some data indicate possible increases in self-reported physical activity in those 65 years and older (Caspersen et al., 2000), negative trends in physical activity participation are corroborated by objective surveillance data (Davis \& Fox, 2006; Troiano et al., 2008). One such study estimated that older adults ( $M$ age $=76$ years) average about two-thirds of the estimated physical activity energy expenditure and perform half as many minutes of moderate physical activity as younger adults ( $\mathrm{M}$ age $=27$ years; Davis \& Fox, 2006). These trends continue across old age with an increasing proportion of older adults engaging in no leisure time physical 
activity (e.g., 65-74 years or "young old" at $46 \%$ versus $75+$ or "middle/old old" years at $56 \%$ ), less moderate and vigorous physical activity $(26 \%$ \& $18 \%$ versus $15 \%$ \& $8 \%$ for moderate and vigorous physical activity for "young old" and "middle/old old", respectively), and fewer older adults meeting current physical activity guidelines with advancing age (Pleis et al., 2009; Tucker et al., 2011). Overall, nearly 52\% of older adults report engaging in no leisure-time physical activity (Barnes, 2007).

There are motivational changes in terms of what drives older adults to adopt or maintain physical activity. Older adults are less likely to be motivated by appearance or body image than young adults (Brunet \& Sabiston, 2011) and instead choose to stay active to maintain their physical and mental health, functional independence, and for social benefits (Belza et al., 2004; Cohen-Mansfield, Marx, Biddison, \& Guralnik, 2004). Additionally, health problems and functional limitations present barriers to physical activity participation for many older adults that were not present in younger age (Belza et al., 2004; Brawley, Rejeski, \& King, 2003; CohenMansfield et al., 2004; Schutzer \& Graves, 2004). Older adults report walking as their activity of choice (Belza et al., 2004) and self-report averaging approximately 3.6 hours of walking per week (Salmon, Owen, Crawford, Bauman, \& Sallis, 2003). It may be that preferred less intense physical activity, such as walking, replaces more vigorous physical activities that were performed during younger age, so that less energy is expended in old age. Changes in motivation, abilities (actual and perceived), and preferences may help explain the decline of physical activity present in old age.

\subsubsection{Wellbeing}

Although both young and old adults have expectations that they will become less happy as they age, cross-sectional comparisons show a tendency for older people to report more happiness (Lacey, Smith, \& Ubel, 2006) and more positivity of affect (Carstensen et al., 2011, 2000; Gross et al., 1997) than their younger counterparts. The increase in positivity drops off at age 60, suggesting there may be a point in the lifespan where affect stops becoming more positive, and instead stabilizes or even declines (Carstensen et al., 2011; Charles et al., 2001). The decrease in positivity of affect in older years, however, does not compare in magnitude to the increase in positivity that occurred in adulthood. Although there is some evidence that life satisfaction increases in a linear fashion with age (Prenda \& Lachman, 2001), other studies show that satisfaction with life peaks in midlife (Lang \& Heckhausen, 2001) or between age 65 and 70, gradually decreasing thereafter (Mroczek \& Spiro, 2005).

Shifts in motivation and emotion regulation may help explain the enhancement of wellbeing seen in old age. Older adults show more flexibility in adjusting goals than younger adults and regulate goals with the primary purpose of avoiding losses as opposed to striving for gains (Heckhausen, Wrosch, \& Schulz, 2010; Heckhausen, 1997). Namely, older adults are more likely to disengage from unobtainable or unrealistic goals and are more likely to adopt more age-appropriate goals. Compared to younger adults, older adults are also more likely to view themselves as healthier or more exceptional when compared to others (Heckhausen, 1997). These adaptive tendencies help older adults optimize their development by protecting their self-esteem and motivational resources from the negative impact of failure or loss experiences (Heckhausen et al., 2010). The constraints on time horizons in old age (i.e., perceived limits on future time) may also continue to shift motivation towards regulation of emotional states (e.g., appreciating life or being happy) over other types of goals (Carstensen et al., 1999). These motivational shifts are likely to have implications for wellbeing in old age. 


\subsubsection{Physical activity and wellbeing}

Cross-sectional and longitudinal data indicate that physical activity indirectly enhances satisfaction with life in old age through its influence on affect, mental health, and self-efficacy (Elavsky et al., 2005; McAuley et al., 2006). For example, McAuley and colleagues (2006) showed that greater amounts of physical activity were associated with greater self-efficacy, which was associated with more positive physical and mental health. In turn, health status was positively related to satisfaction with life. Elavsky and colleagues (2005) found that self-efficacy and positive affect were significant mediators of the association between physical activity and wellbeing (i.e. global quality of life) at a 1-year follow-up of a physical activity intervention for older adults, and that changes in positive affect mediated this relation across an additional four years of follow-up.

\subsection{Summary}

Based on the current literature, it seems that the highest levels of physical activity seem to occur in childhood, followed by a steep drop-off in adolescence, continued decline in emerging adulthood, stabilization in adulthood, and another drop-off in old age (see Figure 1). In contrast, wellbeing seems to start high in childhood, drop-off throughout adolescence, emerging adulthood, and adulthood, increase in old age, and gradually decline in the oldest age (see Figure 2 below). Although physical activity has been shown to be linked to wellbeing at different ages, little is understood about how the link between physical activity and wellbeing changes across life stages.

Figure 1. A representative schematic of how physical activity changes across the lifespan including how individual differences (sex), life events (first child), and daily changes may impact the trajectory

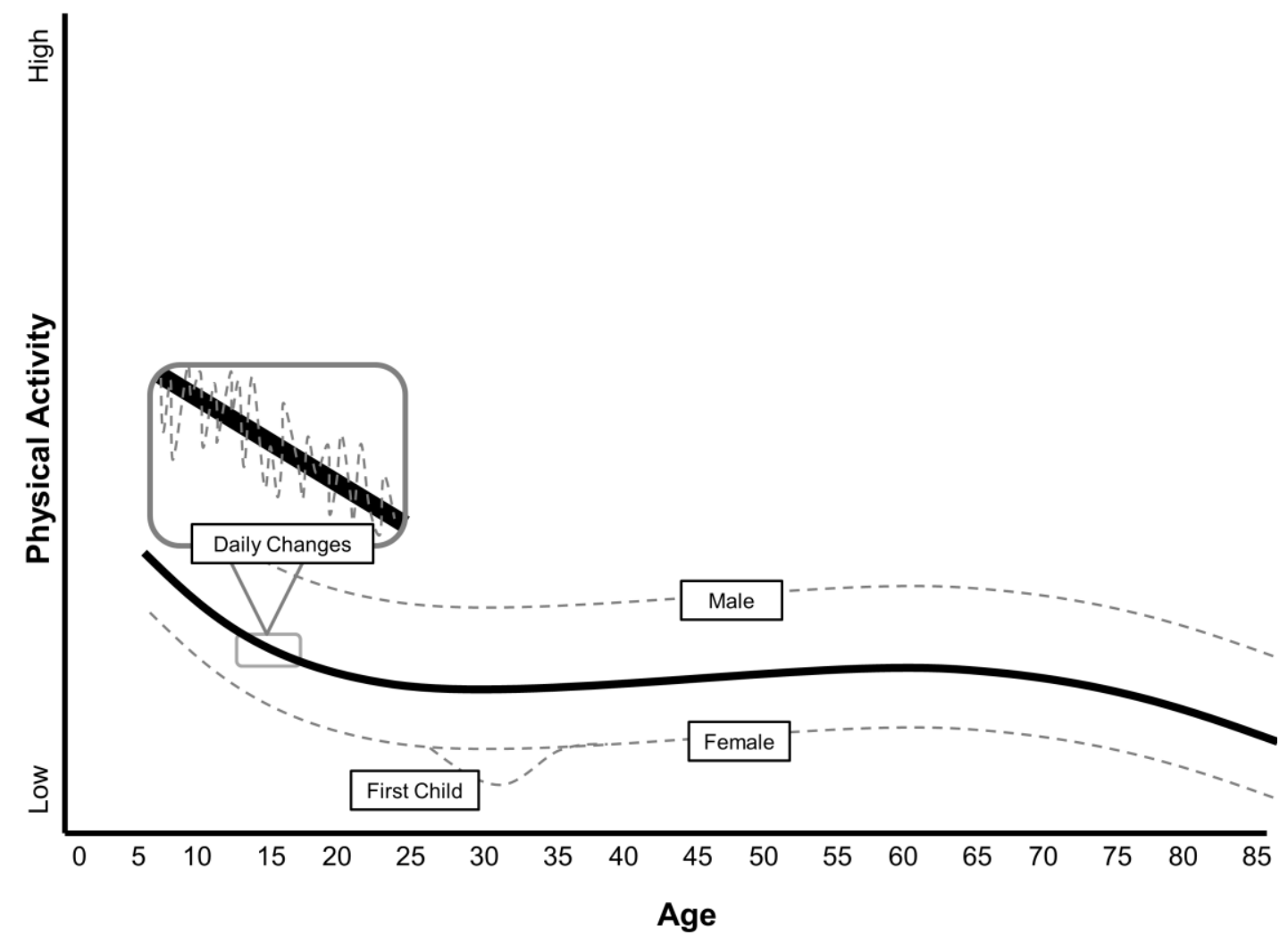


Figure 2. A representative schematic of how wellbeing changes across the lifespan including how individual differences (extraversion), life events (widowhood), and daily changes may impact the trajectory

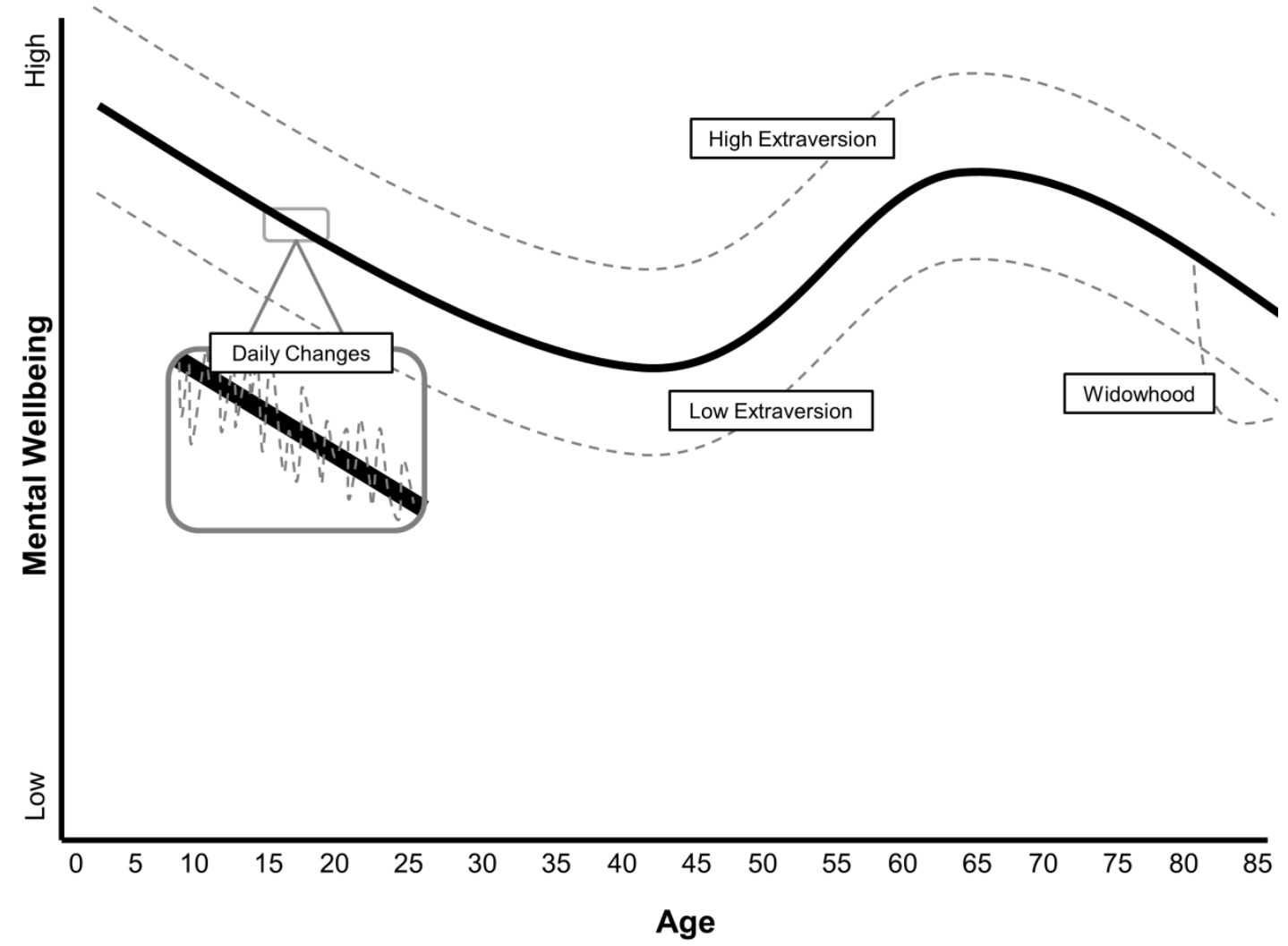

\section{Interpersonal and intrapersonal differences}

It is important to note that the trajectory of physical activity and wellbeing across the lifespan is oversimplified when considered as general trends (Baltes et al., 1980; Baltes, 1987; Nesselroade \& Ram, 2004; Ram \& Gerstorf, 2009). Taking a lifespan perspective also includes considering how physical activity and wellbeing vary at interpersonal and intrapersonal levels, and how these differences can vary across life stages. Following, we will discuss how individual differences, life events, and daily changes may impact trajectories of physical activity and wellbeing. Examples of each are also depicted in Figures 1 and 2 (see Appendices).

\subsection{Physical activity}

Strong evidence suggests that physical activity varies systematically as a function of certain individual differences. For example, people who are more extraverted and less neurotic tend to participate in more physical activity than their counterparts (Rhodes \& Smith, 2006). Additionally, males are typically more physically active than females across the lifespan (Caspersen et al., 2000; Sallis et al., 2000; Trost, Pate, et al., 2002). Physical activity also varies on an intrapersonal level. Studies with repeated assessments of physical activity tend to show that half of the variability in physical activity is attributable to intrapersonal change (Conroy, Elavsky, Hyde, \& Doerksen, 2011; Hyde et al., 2011; Matthews, Ainsworth, Thompson, \& Bassett, 2002).

Beyond intrapersonal changes in physical activity across life stages, physical activity also changes in accordance with major life events. For example, getting married or having a first child tends to decrease physical activity participation levels (Brown \& Trost, 2003). 
Intrapersonal variability of physical activity is also present on shorter time scales. For example, intrapersonal fluctuations in physical activity has been shown to systematically vary between weekdays and weekends (e.g., Conroy et al., 2011; Matthews et al., 2002; Trost, Pate, Freedson, Sallis, \& Taylor, 2000). Differences between people, major life-changing events, and minor differences between days can impact physical activity participation.

\subsection{Wellbeing}

Not surprisingly, some people are happier and more satisfied with their lives than others. Some variability in wellbeing is heritable through a temperamental predisposition for positivity and satisfaction with life (Diener et al., 1999). Other interpersonal variability is attributable to traits. Several studies show that people who are more extraverted and less neurotic tend to have higher wellbeing than their counterparts (Costa \& McCrae, 1980; Diener et al., 1999; Hayes \& Joseph, 2003; Huebner, 1991; Larsen \& Ketelaar, 1991). Additionally, life events such as getting married, having children, or widowhood have been shown to greatly impact wellbeing (Clark \& Oswald, 2002). Most studies have focused on explaining interpersonal differences in wellbeing, but positivity and satisfaction with life have been shown to vary at an intrapersonal level (Fujita \& Diener, 2005; Heller, Watson, \& Ilies, 2006; Hyde et al., 2011; Maher et al., 2012; Röcke, Li, \& Smith, 2009; Suh, Diener, \& Fujita, 1996; Watson, 1988). Most repeated assessment studies found that intrapersonal fluctuations account for more than half of the variability in positivity and satisfaction with life.

We have addressed intrapersonal changes in wellbeing across life stages, but wellbeing also systematically varies as a function of certain major life events. For example, marriage and widowhood lead to increases and decreases in wellbeing, respectively (Diener, 2000; Gove \& Shin, 1989; Winter, Lawton, Casten, \& Sando, 1999). Changes in wellbeing can also be the result of more minor events. Greater social activity, higher physical health, and less perceived stress are related to high fluctuations in wellbeing (Bolger, DeLongis, Kessler, \& Schilling, 1989; Mroczek \& Spiro, 2005; Watson, 1988). Importantly, the amount by which wellbeing fluctuates at an intrapersonal level can depend on life stage. For example, older adults tend to have less variability in positive and negative affect than young adults (Röcke et al., 2009). Similar to physical activity, wellbeing differs between people, and across the lifespan, major life stages, and days.

\section{Gaps in the literature}

This brief review has highlighted several gaps within the literature that need to be addressed. These gaps include (1) descriptions of wellbeing in childhood, (2) tests of links between physical activity and wellbeing in childhood, (3) tests of links between physical activity and preponderance of positive affect in adolescence, (4) tests of links between physical activity and satisfaction with life in general adults (i.e., not subpopulations), (5) longitudinal and experimental studies tracking the magnitude and underlying mechanisms of the relation between physical activity and wellbeing across the entire lifespan, and (6) tests of the impact of individual differences and life events on the link between physical activity and wellbeing at different life stages.

\section{Conclusions}

People's affect, behaviors, and cognitions change across life stages and it is likely that these changes (ultimately reflected in changing motivations, behavioral choices, and affective 
regulation) will have notable impact on the processes connecting physical activity and wellbeing. Little is known about how the link between physical activity and wellbeing changes across the lifespan, and even less is understood about causality and underlying mechanisms of this relation. We look forward to research that takes on a lifespan perspective to fill these gaps in physical activity and wellbeing literature. Additionally, this review should serve as an example of how other wellbeing research could benefit from implementing a lifespan perspective.

\section{Authors}

Amanda L. Hyde

Pennsylvania State University

alh379@psu.edu

Jaclyn P. Maher

Pennsylvania State University

Steriani Elavsky

Pennsylvania State University

\section{Publishing Timeline}

Received 10 October 2012

Accepted 9 January 2013

Published 7 March 2013

\section{References}

Arent, S. M., Landers, D. M., \& Etnier, J. L. (2000). The effects of exercise on mood in older adults: A meta-analytic review. Journal of Aging and Physical Activity, 8(4), 407-430.

Argyle, M. (2001). The psychology of happiness (2nd ed.) (Vol. xi). New York, NY, US: Routledge.

Arnett, J. J. (2000). Emerging adulthood: A theory of development from the late teens through the twenties. American Psychologist, 55(5), 469-480. http://dx.doi.org/10.1037/0003-066X.55.5.469

Baltes, P. B. (1987). Theoretical propositions of life-span developmental psychology: On the dynamics between growth and decline. Developmental Psychology, 23(5), 611-626. http://dx.doi.org/10.1037/00121649.23.5.611

Baltes, P. B., Reese, H. W., \& Lipsitt, L. P. (1980). Life-span developmental psychology. Annual Review of Psychology, 31(1), 65-110. http://dx.doi.org/10.1146/annurev.ps.31.020180.000433

Barnes, P. (2007). Physical activity among adults: United States, 2000 and 2005. Hyattsville, MD: US Department of Health and Human Services, CDC.

Belza, B., Walwick, J., Schwartz, S., LoGerfo, J., Shiu-Thornton, S., \& Taylor, M. (2004). Older adult perspectives on physical activity and exercise: Voices from multiple cultures. Preventing Chronic Disease, 1(4), 1-12.

Bolger, N., DeLongis, A., Kessler, R. C., \& Schilling, E. A. (1989). Effects of daily stress on negative mood. Journal of Personality and Social Psychology, 57(5), 808-818. http://dx.doi.org/10.1037/0022-3514.57.5.808

Brawley, L. R., Rejeski, W. J., \& King, A. C. (2003). Promoting physical activity for older adults: The challenges for changing behavior. American Journal of Preventive Medicine, 25(3), 172-183. http://dx.doi.org/10.1016/S0749-3797(03)00182-X

Brown, W. J. \& Trost, S. G. (2003). Life transitions and changing physical activity patterns in young women. American Journal of Preventive Medicine, 25(2), 140-143. http://dx.doi.org/10.1016/S07493797(03)00119-3 
Brownson, R. C., Baker, E. A., Housemann, R. A., Brennan, L. K., \& Bacak, S. J. (2001). Environmental and policy determinants of physical activity in the United States. American Journal of Public Health, 91(12), 1995-2003. http://dx.doi.org/10.2105/AJPH.91.12.1995

Brunet, J. \& Sabiston, C. M. (2011). Exploring motivation for physical activity across the adult lifespan. Psychology of Sport and Exercise, 12(2), 99-105. http://dx.doi.org/10.1016/j.psychsport.2010.09.006

Bukowski, W. M., Hoza, B., \& Boivin, M. (1993). Popularity, friendship, and emotional adjustment during early adolescence. New Directions for Child and Adolescent Development, 1993(60), $23-37$. http://dx.doi.org/10.1002/cd.23219936004

Caldwell, L. L. (2005). Leisure and health: Why is leisure therapeutic? British Journal of Guidance $\mathcal{E}$ Counselling, 33(1), 7-26. http://dx.doi.org/10.1080/03069880412331335939

Carstensen, L. L., Isaacowitz, D. M., \& Charles, S. T. (1999). Taking time seriously: A theory of socioemotional selectivity. American Psychologist, 54(3), 165-181. http://dx.doi.org/10.1037/0003066X.54.3.165

Carstensen, L. L., Pasupathi, M., Mayr, U., \& Nesselroade, J. R. (2000). Emotional experience in everyday life across the adult life span. Journal of Personality and Social Psychology, 79(4), 644. http://dx.doi.org/10.1037/0022-3514.79.4.644

Carstensen, L. L., Turan, B., Scheibe, S., Ram, N., Ersner-Hershfield, H., Samanez-Larkin, G. R., Brooks, K. P., \& Nesselroade, J. R. (2011). Emotional experience improves with age: evidence based on over 10 years of experience sampling. Psychology and Aging, 26(1), 21-33. http://dx.doi.org/10.1037/a0021285

Casey, B. J., Jones, R. M., \& Hare, T. A. (2008). The adolescent brain. Annals of the New York Academy of Sciences, 1124(1), 111-126. http://dx.doi.org/10.1196/annals.1440.010

Caspersen, C. J., Pereira, M. A., \& Curran, K. M. (2000). Changes in physical activity patterns in the United States, by sex and cross-sectional age. Medicine E Science in Sports E Exercise, 32(9), 1601-1609. http://dx.doi.org/10.1097/00005768-200009000-00013

Charles, S. T., Reynolds, C. A., \& Gatz, M. (2001). Age-related differences and change in positive and negative affect over 23 years. Journal of Personality and Social Psychology, 80(1), 136-151. http://dx.doi.org/10.1037/0022-3514.80.1.136

Clark, A. E. \& Oswald, A. J. (2002). A simple statistical method for measuring how life events affect happiness. International Journal of Epidemiology, 31(6), 1139-1144. http://dx.doi.org/10.1093/ije/31.6.1139

Cohen-Mansfield, J., Marx, M. S., Biddison, J. R., \& Guralnik, J. M. (2004). Socio-environmental exercise preferences among older adults. Preventive Medicine, 38(6), 804-811. http://dx.doi.org/10.1016/j.ypmed.2004.01.007

Conroy, D. E., Elavsky, S., Hyde, A. L., \& Doerksen, S. E. (2011). The dynamic nature of physical activity intentions: a within-person perspective on intention-behavior coupling. Journal of Sport $\mathcal{E}$ Exercise Psychology, 33(6), 807-827.

Costa, P. T. \& McCrae, R. R. (1980). Influence of extraversion and neuroticism on subjective well-being: Happy and unhappy people. Journal of Personality and Social Psychology, 38(4), 668-678. http://dx.doi.org/10.1037/0022-3514.38.4.668

Courneya, K. S. \& Friedenreich, C. M. (1999). Physical exercise and quality of life following cancer diagnosis: A literature review. Annals of Behavioral Medicine, 21(2), 171-179. http://dx.doi.org/10.1007/BF02908298

Crews, D. J., Lochbaum, M. R., \& Landers, D. M. (2004). Aerobic physical activity effects on psychological well-being in low-income Hispanic children. Perceptual and Motor Skills, 98(1), 319-324. http://dx.doi.org/10.2466/pms.98.1.319-324

Davis, M. G. \& Fox, K. R. (2006). Physical activity patterns assessed by accelerometry in older people. European Journal of Applied Physiology, 100, 581-589. http://dx.doi.org/10.1007/s00421-006-0320-8

Diener, E. (1984). Subjective well-being. Psychological Bulletin, 95(3), 542-575. http://dx.doi.org/10.1037/0033-2909.95.3.542

Diener, E. (2000). Subjective well-being: The science of happiness and a proposal for a national index. American Psychologist, 55(1), 34-43. http://dx.doi.org/10.1037/0003-066X.55.1.34 
Diener, E. \& Diener, C. (1996). Most people are happy. Psychological Science, 7(3), 181-185. http://dx.doi.org/10.1111/j.1467-9280.1996.tb00354.x

Diener, E. \& Suh, E. M. (1997). Subjective well-being and age: An international analysis. In K. W. Schaie \& M. P. Lawton (Eds.), Annual review of gerontology and geriatrics (Vol. 17, pp. 304-324). New York: Springer.

Diener, E., Suh, E. M., Lucas, R. E., \& Smith, H. L. (1999). Subjective well-being: Three decades of progress. Psychological Bulletin, 125(2), 276-302. http://dx.doi.org/10.1037/0033-2909.125.2.276

Ekkekakis, P. (2003). Pleasure and displeasure from the body: Perspectives from exercise. Cognition $\mathcal{E}$ Emotion, 17(2), 213-239. http://dx.doi.org/10.1080/02699930302292

Ekkekakis, P., Parfitt, G., \& Petruzzello, S. J. (2011). The pleasure and displeasure people feel when they exercise at different intensities. Sports Medicine, 41(8), 641-671. http://dx.doi.org/10.2165/11590680000000000-00000

Elavsky, S. \& McAuley, E. (2005). Physical activity, symptoms, esteem, and life satisfaction during menopause. Maturitas, 52(3), 374-385. http://dx.doi.org/10.1016/j.maturitas.2004.07.014

Elavsky, S., McAuley, E., Motl, R. W., Konopack, J. F., Marquez, D. X., Hu, L., Jerome, G. J., \& Diener, E. (2005). Physical activity enhances long-term quality of life in older adults: Efficacy, esteem, and affective influences. Annals of Behavioral Medicine, 30(2), 138-145. http://dx.doi.org/10.1207/s15324796abm3002_6

Ernst, M., Pine, D. S., \& Hardin, M. (2006). Triadic model of the neurobiology of motivated behavior in adolescence. Psychological Medicine, 36(03), 299-312. http://dx.doi.org/10.1017/S0033291705005891

Fujita, F. \& Diener, E. (2005). Life satisfaction set point: Stability and change. Journal of Personality and Social Psychology, 88(1), 158-164. http://dx.doi.org/10.1037/0022-3514.88.1.158

Gardner, B., De Bruijn, G.-J., \& Lally, P. (2011). A systematic review and meta-analysis of applications of the Self-Report Habit Index to nutrition and physical activity behaviors. Annals of Behavioral Medicine, 42(2), 174-187. http://dx.doi.org/10.1007/s12160-011-9282-0

Gauvin, L., Rejeski, W. J., \& Norris, J. L. (1996). A naturalistic study of the impact of acute physical activity on feeling states and affect of women. Health Psychology, 15, 391-397.

Goldbeck, L., Schmitz, T. G., Besier, T., Herschbach, P., \& Henrich, G. (2007). Life satisfaction decreases during adolescence. Quality of Life Research, 16(6), 969-979. http://dx.doi.org/10.1007/s11136-007-92055

Gove, W. R. \& Shin, H.-C. (1989). The psychological well-being of divorced and widowed men and women: An empirical analysis. Journal of Family Issues, 10(1), 122-144. http://dx.doi.org/10.1177/019251389010001007

Greene, A. L. (1990). Patterns of affectivity in the transition to adolescence. Journal of Experimental Child Psychology, 50(3), 340-356. http://dx.doi.org/10.1016/0022-0965(90)90074-I

Gross, J. J., Carstensen, L. L., Pasupathi, M., Tsai, J., Götestam Skorpen, C., \& Hsu, A. Y. C. (1997). Emotion and aging: Experience, expression, and control. Psychology and Aging, 12(4), 590-599. http://dx.doi.org/10.1037/0882-7974.12.4.590

Gruber, J. J. (1986). Physical activity and self-esteem development in children: A meta-analysis. In G. A. Stull \& H. M. Eckert (Eds.), Effects of physical activity on children (pp. 30-48). Champaign, IL: Human Kinetics.

Halperin, S. (Ed.). (2001). The forgotten half revisited: American youth and young families, 1988-2008. Washington, DC: American Youth Policy Forum.

Hayes, N. \& Joseph, S. (2003). Big 5 correlates of three measures of subjective well-being. Personality and Individual Differences, 34(4), 723-727. http://dx.doi.org/10.1016/S0191-8869(02)00057-0

Heckhausen, J. (1997). Developmental regulation across adulthood: Primary and secondary control of age-related challenges. Developmental Psychology, 33(1), 176-187. http://dx.doi.org/10.1037/00121649.33.1.176

Heckhausen, J., Wrosch, C., \& Schulz, R. (2010). A motivational theory of life-span development. Psychological Review, 117(1), 32-60. http://dx.doi.org/10.1037/a0017668

Heller, D., Watson, D., \& Ilies, R. (2006). The dynamic process of life satisfaction. Journal of Personality, 74(5), 1421-1450. http://dx.doi.org/10.1111/j.1467-6494.2006.00415.x 
Herzog, A. R. \& Rodgers, W. L. (1981). Age and satisfaction: Data from several large surveys. Research on Aging, 3(2), 142-165. http://dx.doi.org/10.1177/016402758132002

Holder, M. D., Coleman, B., \& Wallace, J. M. (2010). Spirituality, religiousness, and happiness in children aged 8-12 years. Journal of Happiness Studies, 11(2), 131-150. http://dx.doi.org/10.1007/s10902-0089126-1

Holder, M. D. \& Klassen, A. (2010). Temperament and happiness in children. Journal of Happiness Studies, 11(4), 419-439. http://dx.doi.org/10.1007/s10902-009-9149-2

Horley, J. \& Lavery, J. J. (1995). Subjective well-being and age. Social Indicators Research, 34(2), 275-282. http://dx.doi.org/10.1007/BF01079200

Huebner, E. S. (1991). Correlates of life satisfaction in children. School Psychology Quarterly, 6(2), 103-111. http://dx.doi.org/10.1037/h0088805

Huebner, E. S. (2004). Research on assessment of life satisfaction of children and adolescents. Social Indicators Research, 66(1), 3-33. http://dx.doi.org/10.1023/B:SOCI.0000007497.57754.e3

Huebner, E. S., Drane, W., \& Valois, R. F. (2000). Levels and demographic correlates of adolescent life satisfaction reports. School Psychology International, 21(3), 281-292.

http://dx.doi.org/10.1177/0143034300213005

Hughes, F. P. (1995). Children, play, and development (2nd ed.). Boston, MA: Allyn and Bacon.

Hyde, A. L., Conroy, D. E., Pincus, A. L., \& Ram, N. (2011). Unpacking the feel-good effect of free-time physical activity: Between- and within-person associations with pleasant-activated feeling states. Journal of Sport \& Exercise Psychology, 33(6), 884-902.

John, O. P. \& Gross, J. J. (2004). Healthy and unhealthy emotion regulation: Personality processes, individual differences, and life span development. Journal of Personality, 72(6), 1301-1334. http://dx.doi.org/10.1111/j.1467-6494.2004.00298.x

Kjønniksen, L., Torsheim, T., \& Wold, B. (2008). Tracking of leisure-time physical activity during adolescence and young adulthood: A 10-year longitudinal study. International Journal of Behavioral Nutrition and Physical Activity, 5(1), 69-79. http://dx.doi.org/10.1186/1479-5868-5-69

Lacey, H. P., Smith, D. M., \& Ubel, P. A. (2006). Hope I die before I get old: Mispredicting happiness across the adult lifespan. Journal of Happiness Studies, 7(2), 167-182. http://dx.doi.org/10.1007/s10902005-2748-7

Lang, F. R. \& Heckhausen, J. (2001). Perceived control over development and subjective well-being: Differential benefits across adulthood. Journal of Personality and Social Psychology, 81(3), 509-523. http://dx.doi.org/10.1037/0022-3514.81.3.509

Larsen, R. J. \& Ketelaar, T. (1991). Personality and susceptibility to positive and negative emotional states. Journal of Personality and Social Psychology, 61(1), 132-140. http://dx.doi.org/10.1037/00223514.61.1.132

Larson, R. W. \& Ham, M. (1993). Stress and 'storm and stress' in early adolescence: The relationship of negative events with dysphoric affect. Developmental Psychology, 29(1), 130-140. http://dx.doi.org/10.1037/0012-1649.29.1.130

Larson, R. W. \& Lampman-Petraitis, C. (1989). Daily emotional states as reported by children and adolescents. Child Development, 1250-1260. http://dx.doi.org/10.2307/1130798

Larson, R. W., Moneta, G., Richards, M. H., \& Wilson, S. (2002). Continuity, stability, and change in daily emotional experience across adolescence. Child Development, 73(4), 1151-1165. http://dx.doi.org/10.1111/1467-8624.00464

Larson, R. W. \& Verma, S. (1999). How children and adolescents spend time across the world: Work, play, and developmental opportunities. Psychological Bulletin, 125(6), 701-736.

http://dx.doi.org/10.1037/0033-2909.125.6.701

Maher, J. P., Doerksen, S. E., Elavsky, S., Hyde, A. L., Pincus, A. L., Ram, N., \& Conroy, D. E. (2012). A daily analysis of physical activity and satisfaction with life in emerging adults. Health Psychology, No Pagination Specified. http://dx.doi.org/10.1037/a0030129

Martin, K. M. \& Huebner, E. S. (2007). Peer victimization and prosocial experiences and emotional wellbeing of middle school students. Psychology in the Schools, 44(2), 199-208.

http://dx.doi.org/10.1002/pits.20216 
Matthews, C. E., Ainsworth, B. E., Thompson, R. W., \& Bassett, D. R. (2002). Sources of variance in daily physical activity levels as measured by an accelerometer. Medicine E Science in Sports E Exercise, 34(8), 1376-1381. http://dx.doi.org/10.1097/00005768-200208000-00021

McAuley, E., Konopack, J. F., Motl, R. W., Morris, K. S., Doerksen, S. E., \& Rosengren, K. R. (2006). Physical activity and quality of life in older adults: Influence of health status and self-efficacy. Annals of Behavioral Medicine, 31(1), 99-103. http://dx.doi.org/10.1207/s15324796abm3101_14

McIntyre, C. W. \& Watson, D. (1990). The effects of social interaction, exercise, and test stress on positive and negative affect. Bulletin of the Psychonomic Society, 28(2), 141-143.

Moneta, G. B., Schneider, B., \& Csikszentmihalyi, M. (2001). A longitudinal study of the self-concept and experiential components of self-worth and affect across adolescence. Applied Developmental Science, 5(3), 125-142. http://dx.doi.org/10.1207/S1532480XADS0503_2

Mroczek, D. K. \& Spiro, A. (2005). Change in life satisfaction during adulthood: Findings from the veterans affairs normative aging study. Journal of Personality and Social Psychology, 88(1), 189-202. http://dx.doi.org/10.1037/0022-3514.88.1.189

Mutrie, N. \& Parfitt, G. (1998). Physical activity and its link with mental, social and moral health in young people. In S. J. H. Biddle, J. F. Sallis, \& N. Cavill (Eds.), Young and active? Young people and health-enhancing physical activity: Evidence and implications (pp. 49-68). London, England: Health Education Authority.

Nesselroade, J. R. \& Ram, N. (2004). Studying intraindividual variability: What we have learned that will help us understand lives in context. Research in Human Development, 1(1-2), 9-29. http://dx.doi.org/10.1080/15427609.2004.9683328

Netz, Y., Wu, M. J., Becker, B. J., \& Tenenbaum, G. (2005). Physical activity and psychological well-being in advanced age: A meta-analysis of intervention studies. Psychology and Aging, 20(2), 272. http://dx.doi.org/10.1037/0882-7974.20.2.272

Nurmi, J.-E. (1992). Age differences in adult life goals, concerns, and their temporal extension: A life course approach to future-oriented motivation. International Journal of Behavioral Development, 15(4), 487-508.

Parfitt, G. \& Eston, R. G. (2005). The relationship between children's habitual activity level and psychological well-being. Acta Paediatrica, 94(12), 1791-1797.

Pate, R. R., Freedson, P. S., Sallis, J. F., Taylor, W. C., Sirard, J., Trost, S. G., \& Dowda, M. (2002). Compliance with physical activity guidelines: Prevalence in a population of children and youth. Annals of Epidemiology, 12(5), 303-308. http://dx.doi.org/10.1016/S1047-2797(01)00263-0

Penedo, F. J. \& Dahn, J. R. (2005). Exercise and well-being: A review of mental and physical health benefits associated with physical activity. Current Opinion in Psychiatry, 18(2), 189-193. http://dx.doi.org/10.1097/00001504-200503000-00013

Physical Activity Guidelines Advisory Committee. (2008). Physical activity guidelines advisory committee report. Washington, DC: U.S. Department of Health and Human Services.

Pleis, J. R., Lucas, J. W., \& Ward, B. W. (2009). Summary health statistics for U.S. adults: National Health Interview Survey, 2008. Vital and Health Statistics. Series 10, Data from the National Health Survey, (242), 1-157.

Prenda, K. M. \& Lachman, M. E. (2001). Planning for the future: A life management strategy for increasing control and life satisfaction in adulthood. Psychology and Aging, 16(2), 206-216. http://dx.doi.org/10.1037/0882-7974.16.2.206

Proctor, C. L., Linley, P. A., \& Maltby, J. (2009). Youth life satisfaction: A review of the literature. Journal of Happiness Studies, 10(5), 583-630. http://dx.doi.org/10.1007/s10902-008-9110-9

Ram, N. \& Gerstorf, D. (2009). Time-structured and net intraindividual variability: Tools for examining the development of dynamic characteristics and processes. Psychology and Aging, 24(4), 778-791. http://dx.doi.org/10.1037/a0017915

Reed, J. \& Buck, S. (2009). The effect of regular aerobic exercise on positive-activated affect: A metaanalysis. Psychology of Sport and Exercise, 10(6), 581-594.

http://dx.doi.org/10.1016/j.psychsport.2009.05.009 
Reed, J. \& Ones, D. S. (2006). The effect of acute aerobic exercise on positive activated affect: A metaanalysis. Psychology of Sport and Exercise, 7(5), 477-514. http://dx.doi.org/10.1016/j.psychsport.2005.11.003

Rejeski, W. J. \& Mihalko, S. L. (2001). Physical activity and quality of life in older adults. The Journals of Gerontology Series A: Biological Sciences and Medical Sciences, 56(Supplement 2), 23-35. http://dx.doi.org/10.1093/gerona/56.suppl_2.23

Rhodes, R. E. \& Smith, N. E. I. (2006). Personality correlates of physical activity: A review and metaanalysis. British Journal of Sports Medicine, 40(12), 958-965. http://dx.doi.org/10.1136/bjsm.2006.028860

Riddoch, C. J., Andersen, L. B., Wedderkopp, N., Harro, M., Klasson-Heggebø, L., Sardinha, L. B., Cooper, A. R., \& Ekelund, U. L. F. (2004). Physical activity levels and patterns of 9- and 15-yr-old European children. Medicine $\mathcal{E}$ Science in Sports $\mathcal{E}$ Exercise, 36(1), 86-92. http://dx.doi.org/10.1249/01.MSS.0000106174.43932.92

Röcke, C., Li, S.-C., \& Smith, J. (2009). Intraindividual variability in positive and negative affect over 45 days: Do older adults fluctuate less than young adults? Psychology and Aging, 24(4), 863-878. http://dx.doi.org/10.1037/a0016276

Ryan, R. M. \& Deci, E. L. (2000). Self-determination theory and the facilitation of intrinsic motivation, social development, and well-being. American Psychologist, 55(1), 68-78. http://dx.doi.org/10.1037/0003-066X.55.1.68

Sallis, J. F., Alcaraz, J. E., McKenzie, T. L., \& Hovell, M. F. (1999). Predictors of change in children's physical activity over 20 months: Variations by gender and level of adiposity. American Journal of Preventive Medicine, 16(3), 222-229. http://dx.doi.org/10.1016/S0749-3797(98)00154-8

Sallis, J. F., Prochaska, J. J., \& Taylor, W. C. (2000). A review of correlates of physical activity of children and adolescents. Medicine $\mathcal{E}$ Science in Sports E Exercise, 32(5), 963-975. http://dx.doi.org/10.1097/00005768-200005000-00014

Salmon, J., Owen, N., Crawford, D., Bauman, A., \& Sallis, J. F. (2003). Physical activity and sedentary behavior: A population-based study of barriers, enjoyment, and preference. Health Psychology, 22(2), 178-188. http://dx.doi.org/10.1037/0278-6133.22.2.178

Schneider, M., Dunn, A., \& Cooper, D. (2009). Affect, exercise, and physical activity among healthy adolescents. Journal of Sport E Exercise Psychology, 31(6), 706-723.

Schneider, M. \& Graham, D. (2009). Personality, physical fitness, and affective response to exercise among adolescents. Medicine and Science in Sports and Exercise, 41(4), 947-955. http://dx.doi.org/10.1249/MSS.0b013e31818de009

Schutzer, K. A. \& Graves, B. S. (2004). Barriers and motivations to exercise in older adults. Preventive Medicine, 39(5), 1056-1061. http://dx.doi.org/10.1016/j.ypmed.2004.04.003

Sliwinski, M. J., Almeida, D. M., Smyth, J., \& Stawski, R. S. (2009). Intraindividual change and variability in daily stress processes: Findings from two measurement-burst diary studies. Psychology and Aging, 24(4), 828-840. http://dx.doi.org/10.1037/a0017925

Stephens, T. (1988). Physical activity and mental health in the United States and Canada: Evidence from four population surveys. Preventive Medicine, 17(1), 35-47. http://dx.doi.org/10.1016/00917435(88)90070-9

Stone, A. A., Schwartz, J. E., Broderick, J. E., \& Deaton, A. (2010). A snapshot of the age distribution of psychological well-being in the United States. Proceedings of the National Academy of Sciences, 107(22), 9985-9990. http://dx.doi.org/10.1073/pnas.1003744107

Strauss, R. S., Rodzilsky, D., Burack, G., \& Colin, M. (2001). Psychosocial correlates of physical activity in healthy children. Archives of Pediatrics and Adolescent Medicine, 155(8), 897-902.

Strong, W. B., Malina, R. M., Blimkie, C. J. R., Daniels, S. R., Dishman, R. K., Gutin, B., Herenroeder, A. C., Must, A., Nixon, P. A., Pivarnik, J. M., \& Trudeau, F. (2005). Evidence based physical activity for school-age youth. The Journal of Pediatrics, 146(6), 732-737.

http://dx.doi.org/10.1016/j.jpeds.2005.01.055

Suh, E., Diener, E., \& Fujita, F. (1996). Events and subjective well-being: Only recent events matter. Journal of Personality and Social Psychology, 70(5), 1091-1102. http://dx.doi.org/10.1037/00223514.70.5.1091 
Telama, R. \& Yang, X. (2000). Decline of physical activity from youth to young adulthood in Finland. Medicine \& Science in Sports \& Exercise, 32(9), 1617-1622. http://dx.doi.org/10.1097/00005768200009000-00015

Troiano, R. P., Berrigan, D., Dodd, K. W., Mâsse, L. C., Tilert, T., \& McDowell, M. (2008). Physical activity in the United States measured by accelerometer. Medicine \& Science in Sports \& Exercise, 40(1), 181188.

Trost, S. G., Owen, N., Bauman, A. E., Sallis, J. F., \& Brown, W. (2002). Correlates of adults' participation in physical activity: Review and update. Medicine \& Science in Sports \& Exercise, 34(12), 1996-2001. http://dx.doi.org/10.1097/00005768-200212000-00020

Trost, S. G., Pate, R. R., Freedson, P. S., Sallis, J. F., \& Taylor, W. C. (2000). Using objective physical activity measures with youth: How many days of monitoring are needed? Medicine $\mathcal{E}$ Science in Sports \& Exercise, 32(2), 426-431. http://dx.doi.org/10.1097/00005768-200002000-00025

Trost, S. G., Pate, R. R., Sallis, J. F., Freedson, P. S., Taylor, W. C., Dowda, M., \& Sirard, J. (2002). Age and gender differences in objectively measured physical activity in youth. Medicine $\mathcal{E}$ Science in Sports $\mathcal{E}$ Exercise, 34(2), 350-355. http://dx.doi.org/10.1097/00005768-200202000-00025

Tucker, J. M., Welk, G. J., \& Beyler, N. K. (2011). Physical Activity in U.S. adults: Compliance with the physical activity guidelines for Americans. American Journal of Preventive Medicine, 40(4), 454-461. http://dx.doi.org/10.1016/j.amepre.2010.12.016

Valois, R. F., Zullig, K. J., Huebner, E. S., \& Drane, J. W. (2004). Physical activity behaviors and perceived life satisfaction among public high school adolescents. Journal of School Health, 74(2), 59-65. http://dx.doi.org/10.1111/j.1746-1561.2004.tb04201.x

Verplanken, B. \& Melkevik, O. (2008). Predicting habit: The case of physical exercise. Psychology of Sport and Exercise, 9(1), 15-26. http://dx.doi.org/10.1016/j.psychsport.2007.01.002

Verplanken, B. \& Wood, W. (2006). Interventions to break and create consumer habits. Journal of Public Policy \& Marketing, 25(1), 90-103. http://dx.doi.org/10.1509/jppm.25.1.90

Watson, D. (1988). Intraindividual and interindividual analyses of positive and negative affect: Their relation to health complaints, perceived stress, and daily activities. Journal of Personality and Social Psychology, 54(6), 1020-1030. http://dx.doi.org/10.1037/0022-3514.54.6.1020

Weiss, M. R. (2000). Motivating kids in physical activity. President's Council on Physical Fitness and Sports Research Digest, 3(11), 1-8.

Williamson, D., Dewey, A., \& Steinberg, H. (2001). Mood change through physical exercise in nine- to ten-year-old children. Perceptual and Motor Skills, 93(1), 311-316. http://dx.doi.org/10.2466/pms.2001.93.1.311

Winter, L., Lawton, M. P., Casten, R. J., \& Sando, R. L. (1999). The relationship between external events and affect states in older people. International Journal of Human Development and Aging, 50, 1-12.

Wood, W. \& Neal, D. T. (2007). A new look at habits and the habit-goal interface. Psychological Review, 114(4), 843-863. http://dx.doi.org/10.1037/0033-295X.114.4.843

Yurgelun-Todd, D. (2007). Emotional and cognitive changes during adolescence. Current Opinion in Neurobiology, 17(2), 251-257. http://dx.doi.org/10.1016/j.conb.2007.03.009 